\title{
On the Difference between Staff in a Sino-Western Joint Venture
}

\author{
Qiang Huang \\ School of Foreign Languages, Sichuan University of Science and Engineering \\ 180, Xueyuan Street, Huixing Road, Zigong 643000, Sichuan, China \\ E-mail: johnqhuang@tom.com
}

\begin{abstract}
Being a vast market and with relatively cheap labour cost, China has increasingly attracted foreign investors mainly from western developed countries to establish joint ventures. This has benefited each party concerned. However, some diversities or even conflicts have emerged due to different cultures, ways of thinking, behaviours and words among Chinese and western staff. This paper enumerates some of these diversities and intends to find the cause of them and give those future investors to China some guidelines to avoid those disputes in their business activities.
\end{abstract}

Keywords: Difference, Sino-western staff, Cause

\section{Introduction}

In a Sino-western joint venture, the staff may comes from a western country or even from several countries, who would be diverse in the dominant language used and in cultural orientation.These diversities always cause many misunderstandings and constitute a bad obstacle to communication. Therefore, it is quite necessary to find out those diversities and main causes of them and obtain some practical communication skills to avoid the interference.

\section{The Various Differences in a Joint Venture}

\subsection{The difference in greeting}

In a Chinese company, if the colleagues meet each other in the morning in a lift, they always say, "What did you do last night? Have you eaten breakfast?" Chinese think their greeting is a way to show cares to the colleague. However, when a western colleague hears it, he/she will be surprised and confused. He/she will think what he/she did last night is his/her privacy. However, in greeting between westerns, expressions such as "Good morning, how are you ? hi or hello", are more common.

\subsection{The difference in appellation}

In China, people usually call the seniors "grandpa or grandma"; the middle-aged "uncle or aunt "; the youngster "brother or sister" and prefer to call one's business or technical title, such as Huang Jingli (Chinese pin yin)-Manager Huang, Chen Gong-Engineer Chen etc. However, in the west, the way people call other person's name is far different from that of Chinese. Chinese may consider some of the western appellation as impolite and rude. For instance, some children call the seniors directly their names instead of calling them grandpa or grandma, which is unacceptable in China. So, in a Sino-western joint venture, we may call the manager or engineer "manager Huang or engineer Chen". However, nowadays in China, "Mr. or Ms" is quite common and acceptable.

\subsection{The difference in dietetic rites}

Chinese are always hospitable. At dinner table, zealous Chinese are used to fill wine or fetch food for each other. They may say some humble words like "my food is not enough; my food may not be very good" even if there is a lot of delicious food on the table. Chinese people always try to persuade the guests to eat especially drink more. In the west, people always do not want the others to serve what they do not like. However, in a Sino-western joint venture, the western need not treat your Chinese colleague as above mentioned rites. You just need to enjoy your delicious dish. It is polity enough.

\subsection{The difference regarding privacy}

Chinese pay much attention to their intimacy and people around them. They are told an individual belongs to a collective. They have received this conception when they were little children. One would like to know other people's private stories and make others know his/her own as well, such matter as salary, boy friend, girl friend, 
age, the price of their belongings etc. However, a western may dislike other people to know his privacy and wants to keep a private space. So, in primal communication with Chines colleagues, if one is asked about his/her privacy, do not be surprised and forgive their indeliberatness. They just want to show you their cares. However, a western can ask any questions you like to your Chinese colleague.

\subsection{The difference in behavioural principle}

Chinese think humility is a virtue. When contacting others, they always observe one communication principle of Chinese style, i.e. treating themselves humbly while treating others respectfully. This is a polite phenomenon full of Chinese cultural feature. When praisd by others, Chinese always say, "No, no... I'm not good at...", "I have not done it well". When they are assigned a task, they usually say "I am afraid I cannot do it well; I just have a try". In fact, they are completely capable of doing the business well. However, in the west, there is no such modest practice. When praised by others, westerns are always very happy and say, "thank you!" to express their acceptance. Therefore, when an western hears Chinese are trying to be humble, he/she should confirm with the Chinese if they are really incapable or they are expressing humility and do not regard they are dishonest.

\subsection{The difference in time conception}

The westerns always regard time as money, so they cherish the time. In their daily life, they always make an elaborate schedule for their working time or spare time and they also execute it strictly. They hope their colleagues could be punctual. Chinese may a little idle and many Chinese have the habit of noon nap, which may cause a little conflict between Chinese and western. However, the situation has been changed a lot thanks to the integration into the global track. Most of Chinese can be punctual and quite serious to time and even do overtime job voluntarily.

\subsection{The difference in creativity}

In a Chinese company, a manager may require the staff to obey his order strictly. He/she does not like the staff to have too many different thoughts or ideas of their own. The manager may think it is too difficult to control his/her underlings if they have too many different ideas. Therefore, the individualism in a Chinese company is not popular. On the contrary, in western countries, creativity of the staff is encouraged. The boss favors the underlings who are creative and active. Because he/she thinks this kind of staff could create the ultimate profit for the company. They believe if everyone tries his best to gain the maximal profit, the company will get the best achievement. For this matter, a western employee may find a indirect and connotative way to put forward your suggestions to the manager and avoid putting him/her in an embarrassed circumstance particularly in the public.

The above enumerated are some common and popular differences between Chinese and western staff, and finding out the main causes for these issues may help mutual understanding between them.

\section{Some Causes of the Differences}

\subsection{The culture and language}

Language is an important part of culture, and it is also an important carrier of culture. The language from different cultures may cause ambiguity and misunderstanding in communication. The different language practice influences the veracity of the communication heavily. Chinese culture mainly originates from Confucian philosophy, in which comity is one of its cores and the direct cause of Chinese dietetic rites. Therefore, Chinese culture is always very implicit, and when Chinese people express their mind, they usually use moderate languages and body action instead of the obvious, direct and exact words. Every Chinese seem to be very humble, moderate and indirect in daily life and office.

\subsection{The authority and democracy}

Ethic of dignity and humility are another core of Chinese Confucian philosophy. It avers the lower estate should obey the higher one. The core of this spirit is loyalty and filial piety. Chinese used to adore authority. They obey and depend on an authority. They are royal to the manager and willing to obey the leaders' order. They always ask for the agreement of the leaders' when dealing with business; all decisions are usually from a collective rather than an individual, which may delay the implementation of a decision. On the contrary, the democracy and freedom widely exist in the western society. The society has little control to the individual personality. The core of the character feature of the western is freedom and independence. Therefore, western employees may have to reserve their individualism in a sino-western joint venture and submit their different opinion in a moderate way.

\subsection{The behavioural criterion}

Behavior criterion is ethics and behavior rules that are acceptable by a society. In short, it is a rule that tells people what should be done and what should not be done. People from different societies always use their own 
behavior criterion to judge other's behavior whether it is reasonable or not. As the different behavior criterions between the Chinese and the western, there are always many misunderstandings or unpleasant matter, such as asking for privacy. So to ensure a friendly communication between Chinese and the western, it is necessary for both to understand each behavior criterion. We should make clear what is allowed and what is forbidden regarding to their different behavior criterion.

\section{Conclusion}

The behaviour disputes do exist among people even from a same cultural background, let alone from different countries and cultures. Therefore, comprehending the cultural and behavioural differences can help us avoid some unnecessary trouble. Both Chinese and western employees should learn more about the opposite culture and try to find out the effective way to avoid the conflicts arising from it. Only in this way can the business be carried out harmoniously and effectively.

\section{References}

Kemp, Ron. (1999). Cooperation and conflict in international joint venture relationship. University of Groningen, Research Institute SOM Research Report with number 99B33.

LG, Franko. (2007). Joint venture survival in multinational corporations. America: Praeger Publishers.

Richard, Germain. (1998). Sustaining Satisfactory Joint Venture Relationships: The Role of Conflict Resolution Strategy. Journal of International Business Studies, Vol. 29.

Yin, Bajie. (2005). Everyday business English. Tianjin: Nankai University Publishing House, China.

Zeng, Shiqiang. (2004). Interpersonal relationship and communication. Tsinghua University Publishing House. 